\title{
Use of symptom-focused oncological cancer therapies in hospices: a retrospective analysis
}

Ulrich Kaiser ${ }^{1}$, Ursula Vehling-Kaiser ${ }^{2}$, Fabian Kück ${ }^{3}$, Nicolae-Catalin Mechie ${ }^{4}$, Ana Hoffmann ${ }^{2}$ and Florian Kaiser ${ }^{5^{*}}$

\begin{abstract}
Background: There is controversy regarding the practical implementation of symptom-focused oncological cancer therapies to hospice residents. In this study, we aim to analyse the use and indication of supportive-oncological cancer therapies in hospices.
\end{abstract}

Methods: We conducted a retrospective survey of all residents of two hospice centres in the government district of Lower Bavaria, Germany. Hospice $1(\mathrm{H} 1)$ was a member of an oncological-palliative medical network, and hospice $2(\mathrm{H} 2)$ was independently organized. The evaluation period was the first 40 months after the opening of the respective hospice care centre. Demographical and epidemiological data as well as indications and type of supportive-oncological cancer therapies were recorded. A descriptive analysis and statistical tests were performed.

Results: Of the 706 residents, 645 had an underlying malignant disease. The average age was 72 years and the mean residence time was 28 days. The most frequent cancer types were gastrointestinal cancers, gynaecological cancers and bronchial carcinomas. Overall 39 residents (33 in $\mathrm{H} 1$ and 6 in $\mathrm{H} 2, p<0.01$ ) received symptom-focused oncological cancer therapy. The average age of these residents was 68 years, and the mean residence time was 55 days. The most common therapeutic indications were dyspnoea and pain. The most common symptom-focused oncological cancer therapies were bisphosphonates, transfusions (erythrocyte- and platelet- concentrates), radiotherapy and anti-proliferative drugs (chemotherapy, anti-hormonal- and targeted- therapies). Patients with therapy lived significantly longer than patients without therapy $(p<0.01)$.

Conclusions: Symptom-focused oncological cancer therapies can be implemented in hospices; however, their implementation seems to require certain structural and organizational prerequisites as well as careful patient selection. As a palliative medical approach, the focus is to ameliorate the symptoms and not prolong life. Symptom-focused oncology treatment could be a further and important part for the therapy of hospice patients in the future.

Keywords: Symptom-focused oncological cancer therapy, Hospice, Symptom relief

\footnotetext{
* Correspondence: florian.kaiser@med.uni-goettingen.de

${ }^{5}$ University Medicine Göttingen, Clinic for Haematology and Medical

Oncology, Robert-Koch-Straße 40, 37075 Göttingen, Germany

Full list of author information is available at the end of the article
}

(c) The Author(s). 2020 Open Access This article is licensed under a Creative Commons Attribution 4.0 International License, which permits use, sharing, adaptation, distribution and reproduction in any medium or format, as long as you give appropriate credit to the original author(s) and the source, provide a link to the Creative Commons licence, and indicate if changes were made. The images or other third party material in this article are included in the article's Creative Commons licence, unless indicated otherwise in a credit line to the material. If material is not included in the article's Creative Commons licence and your intended use is not permitted by statutory regulation or exceeds the permitted use, you will need to obtain permission directly from the copyright holder. To view a copy of this licence, visit http://creativecommons.org/licenses/by/4.0/. The Creative Commons Public Domain Dedication waiver (http://creativecommons.org/publicdomain/zero/1.0/) applies to the data made available in this article, unless otherwise stated in a credit line to the data. 


\section{Background}

Introductory case report: An elderly man (80 years old) was admitted to the hospice because of advanced bronchial carcinoma. He suffered from dyspnoea and weakness due to anaemia ( $\mathrm{Hb} 7-8 \mathrm{~g} / \mathrm{dl}$, no pleura effusions, no stridor) during physical strain, but he managed the daily activities in the hospice. During his daughter's wedding, where $>300$ guests were invited, he wanted to start the wedding reception with a bridal dance. Two erythrocyte concentrates were transfused. As a result the dyspnea and the weakness were improved. The dance was a success; father and daughter were overjoyed, and the guests applauded. A few days later the resident died in the hospice centre. Thus, symptom-focused cancer therapy at the end of life was the subject of this retrospective analysis.

The use of palliative care for the treatment of critically ill patients is increasing. The early use of palliative care during metastatic stages or for previously incurable cancers is becoming increasingly important, particularly in the field of cancer therapy [1-4]. Palliative care focuses on measures to improve the quality of life $[2,3]$ and is often used during early stages of cancer parallel to oncological therapies [5]. In contrast, the implementation of cancer therapies in patients with advanced stages of diseases, especially in hospices, is controversial. However, cancer therapies should be differentiated into oncological therapies, primarily aimed at prolonging life or preventing further cancer growth, and symptom-focused cancer therapies, focused primarily on maintaining or improving the quality of life. Patients, even in advanced disease stages, can benefit from modified symptomoriented cancer therapies [6-13]. A parallel application of cancer therapies and hospice care can be useful [14, 15 ] and even decrease the use of more aggressive therapies [16]. Examples of symptom-controlling oncological therapies are chemotherapy, antihormonal therapies, radiotherapy, bisphosphonates, or transfusions [8-13, $15,17,18]$, which are used in cancer-associated conditions such as symptomatic anaemia/thrombocytopenia, pain, symptomatic bone metastases, or difficult to stop local bleeding. However, the use of cancer therapies must be critically evaluated, particularly during the late stages of life, to prevent a reduction in the quality of life or excessive therapy [19-22]. The more a cancer progresses, the more difficult it becomes to provide the indication for cancer therapies. In particular, the residents of hospices who are in the terminal stage of their illness must always be given special consideration [19]. The decision whether to provide palliative care, hospice care, or further cancer therapy for a patient with a highly advanced stage disease is often very difficult [23]. However, the omission of life-sustaining therapies alone does not seem to be optimum to identify patients who benefit from a hospice [24]. There are indications, that streamlined concepts combining disease-specific therapies and hospice care have advantages over a strict "either/or" concept [25-27].

\section{Methods}

The aim of the study was to determine to what extent and with what indication oncological therapies are still used in hospices of a governmental district in the State of Bavaria, Germany. The basis for a further discourse is to be established in this way.

Therefore, in the sense of a cluster sample, we performed a retrospective analysis in all hospices in Lower Bavaria $(n=2)$. This method was selected for practical and economic reasons. The evaluation period was the first 40 months after opening [Hospice 1 (H1): 09/2013 to $12 / 2016$; Hospice 2 (H2): $07 / 2015$ to $10 / 2018$ ]. For these periods, all residents of the two hospices were included in the study without exception in a first analysis step. The date of birth, age at admission, gender, date of admission, date of death, date of discharge (if applicable) and the underlying main diagnosis were recorded for all residents. In a second examination step, all patients with a malignant haematological or oncological disease as the main diagnosis were included in the further analysis. Patients with a non-malignant main diagnosis were excluded. Further inclusion and exclusion criteria (e.g. age, clinical course and cause of death) did not exist. In this second analysis step, the use and, if available, the indication and type of cancer-specific therapies were included.

Cancer-specific therapy was defined as haematological and oncological therapies (chemotherapy, targeted and anti-hormonal therapies, bisphosphonates, radiotherapy, platelet and erythrocyte transfusions; hereinafter referred to as symptom-focused oncological therapies) that are commonly used to treat malignant diseases. Because checkpoint inhibitors were only approved for individual indications or were not yet approved during the evaluation period, they were not included in the evaluation. Palliative-supportive or general internal therapies such as anti-emetics, pain medication or antibiotics were not considered. Furthermore, demographic and structural data of both hospices were documented.

Medical personnel trained in oncology/palliative medicine and experienced in scientific data collection were assigned to carry out the documentation to ensure a high level of content and quality of the data collected. Data was obtained from the patient files of the respective hospices. For this purpose, a data entry form was created in Microsoft Excel 2010, which was used in both hospices. Content controls were included as part of the data evaluation. In the event of obvious discrepancies, these were checked again using the original documents and corrected if necessary. To guarantee the anonymity of 
the hospice residents, a pseudonymized procedure was selected, in which each resident was assigned a number for further evaluation.

Both the hospice centres had a capacity of 10 beds, with comparable populations of the respective county (H1, 158,025 inhabitants; H2, 119,075 inhabitants). H1, the member of an oncological-palliative medical network, is certified by the European Society for Medical Oncology (ESMO) and located in the immediate vicinity of a hospital and haematological/oncological outpatient clinic. Furthermore, regular hospice conferences are held with palliative care physicians, haematologists/oncologists, general practitioners and nursing staff of the hospice, during which the indications for symptom-focused oncological therapies are discussed on interdisciplinary basis. In $\mathrm{H} 2$ hospice conferences have not yet been established. H2 is independently organized. Medical care in $\mathrm{H} 1$ is provided by general practitioners, haematologists/oncologists and palliative care physicians, whereas in $\mathrm{H} 2$ it is provided by general practitioners and palliative care physicians.

For the comparison of the two hospices and the comparison of patients who received an oncological therapy and patients who did not, we applied Fisher's exact test for binary variables and the Wilcoxon rank sum test with continuity correction for numerical variables since a visual inspection showed that these are not approximately normally distributed. In order to analyse survival times, we generated Kaplan-Meier curves and compared them by performing log-rank tests. Moreover, predictors were identified using multivariate Cox regression models. Due to the exploratory nature of this study, no adjustment for multiple testing was applied. The significance level was set to alpha $=5 \%$ for all statistical tests. All analyses were performed with the statistic software $\mathrm{R}$ (version 3.4.0 [28];) using the R-packages survminer (version 0.4.4 [29];) and survival (version 2.41.3 [30];) for Kaplan-Meier curves and Cox regression models.

According to the Ethics Committee Munich, an ethical approval was not required for this study.

\section{Results}

Entirety of patients with an underlying malignant disease A total of 706 patients were analysed (Table 1); 645 (91\%) suffered from a malignant disease [H1, 312 (93\%) of 336 residents; H2, 333 (90\%) of 370 residents]. In

Table 1 General overview: Patients with malignant primary disease in two hospices

\begin{tabular}{|c|c|c|c|c|c|c|}
\hline \multirow{2}{*}{$\begin{array}{l}\text { Category and related } p \text {-value }{ }^{a} \\
\text { Total number of patients }\end{array}$} & \multicolumn{2}{|c|}{$\begin{array}{l}\text { Hospice } 1 \\
(\mathrm{H} 1)\end{array}$} & \multicolumn{2}{|c|}{$\begin{array}{l}\text { Hospice } 2 \\
(\mathrm{H} 2)\end{array}$} & \multicolumn{2}{|c|}{ Total } \\
\hline & 336 & $100 \%$ & 370 & $100 \%$ & 706 & $100 \%$ \\
\hline Patients with malignant disease & 312 & $93 \%$ & 333 & $90 \%$ & 645 & $91 \%$ \\
\hline \multicolumn{7}{|l|}{ Evaluation: Patients with a malignant disease } \\
\hline Age in years (median, $p=0.98$ ) & \multicolumn{2}{|c|}{$\begin{array}{l}72 \text { (range: } \\
33-96 \text { ) }\end{array}$} & \multicolumn{2}{|c|}{$\begin{array}{l}72 \text { (range: } \\
42-101)\end{array}$} & \multicolumn{2}{|c|}{$\begin{array}{l}72 \text { (range: } \\
33-101)\end{array}$} \\
\hline Residence time in days $(p=0.66)$ & \multicolumn{2}{|c|}{$\begin{array}{l}30 \text { (range: } \\
0-440 \text { ) }\end{array}$} & \multicolumn{2}{|c|}{$\begin{array}{l}26 \text { (range: } \\
0-335 \text { ) }\end{array}$} & \multicolumn{2}{|c|}{$\begin{array}{l}28 \text { (range: } \\
0-440)\end{array}$} \\
\hline \multicolumn{7}{|l|}{ Gender $(p=0.18)$} \\
\hline Male & 141 & $45 \%$ & 132 & $40 \%$ & 273 & $42 \%$ \\
\hline Female & 171 & $55 \%$ & 201 & $60 \%$ & 372 & $58 \%$ \\
\hline \multicolumn{7}{|l|}{ Malignant disease (primary diagnosis) } \\
\hline Bronchial carcinomas $(p=0.92)$ & 56 & $18 \%$ & 61 & $18 \%$ & 117 & $18 \%$ \\
\hline Gastrointestinal cancers $(p=0.67)$ & 97 & $31 \%$ & 98 & $29 \%$ & 195 & $30 \%$ \\
\hline Gynecological cancers $(p=0.03)$ & 47 & $15 \%$ & 73 & $22 \%$ & 120 & $19 \%$ \\
\hline Brain cancers $(p=0.49)$ & 25 & $8 \%$ & 32 & $10 \%$ & 57 & $9 \%$ \\
\hline ENT tract cancers $(p=0.57)$ & 12 & $4 \%$ & 16 & $5 \%$ & 28 & $4 \%$ \\
\hline Other cancer (bone cancers, thyroid carcinomas, skin malignomas, cancer of unknown pirmary; $p=0.72$ ) & 14 & $5 \%$ & 18 & $5 \%$ & 32 & $5 \%$ \\
\hline Urological cancers $(p=0.78)$ & 30 & $10 \%$ & 29 & $9 \%$ & 59 & $9 \%$ \\
\hline Haematological systemic diseases $(p<0.01)$ & 31 & $10 \%$ & 6 & $2 \%$ & 37 & $6 \%$ \\
\hline \multicolumn{7}{|l|}{ Clinical course } \\
\hline Discharge $(p=1.00)$ & 13 & $4 \%$ & 13 & $4 \%$ & 26 & $4 \%$ \\
\hline Hospitalization $(p=0.69)$ & 2 & $1 \%$ & 4 & $1 \%$ & 6 & $1 \%$ \\
\hline For survival time see Fig. 1 & & & & & & \\
\hline
\end{tabular}

a Refers to the comparison of the two hospices 
both hospices the number of women predominated [but no significant difference $(p=0.18)$ ], and the average age was 72 years $(p=0.98)$. The course of the disease was similar in both hospices: the average residence time was 30 days in $\mathrm{H} 1$ and 26 days in $\mathrm{H} 2(p=0.66)$ with a range from zero days to a maximum of 440 days. Only a small number of patients were discharged from the hospice (4\% each, $p=1.00$ ) or transferred to a hospital (1\% each, $p=0.69$ ); the majority died within the first 8 weeks after being admitted to the hospice (Fig. 1: H1, 87.5\%; H2, $85.6 \%, p=0.43$ ).

Among the malignant diseases, gastrointestinal cancers, gynaecological cancers and bronchial carcinomas were most common in both hospices. There was no significant difference in the spread of malignant diseases in both hospices, except haematological systemic diseases that were more common in $\mathrm{H} 1 \quad(p<0.01)$ and gynecological cancers that were more common in $\mathrm{H} 2$ $(p=0.03)$ (Table 1).

\section{Patients in oncological therapy}

A total of 39 of 645 patients (6\%) with an underlying malignant disease underwent symptom-focused oncological therapy (Table 2). The odds of receiving an oncological therapy were significantly higher in $\mathrm{H} 1$ [H1, 33 patients (11\%); H2, 6 patients $(2 \%), p<0.01]$. The average age was similar in both hospices ( $\mathrm{H} 1,69$ years; $\mathrm{H} 2$, 68 years), but slightly lower than all patients with a malignant disease ( $\mathrm{H} 1$ and $\mathrm{H} 2,72$ years respectively); however, there was no significant difference $(p=0.25)$. The residence time for patients with a symptom-focused oncological therapy was longer in H1 (67 days) than in $\mathrm{H} 2$ (44 days). The odds of being discharged from the hospice were significantly lower $(p=0.05)$ and the length of stay was significantly longer for patients who received an oncological therapy compared to patients who did not. $(p<0.01)$. The number of women predominated in both hospices.

In both hospices, the distribution of underlying malignant diseases among patients receiving oncological therapy (Table 2) was similar to the distribution among all the examined patients with a malignant disease (Table $1)$.

We analyzed survival times, i.e. the number of days from admission to death, and obtained that the hazard rate of patients who underwent symptom-focused oncological therapy is significantly different from those without therapy (Fig. 2 and Table 3), even if we control for hospice, age, sex and malignant disease (HR 0.49; $p<$ 0.01). This suggests a lower instantaneous risk of mortality for patients who receive a symptom-focused oncological therapy. The hazard ratios for age (HR 1.01; $p=$ 0.01 ), gender (HR 0.82; $p=0.04$ ), brain cancer (HR 0.62; $p=0.005$ ) and bisphosphonates (HR 0.48; $p=0.03$; Table 4) were significantly different from 1 as well, which indicates that young and female patients and
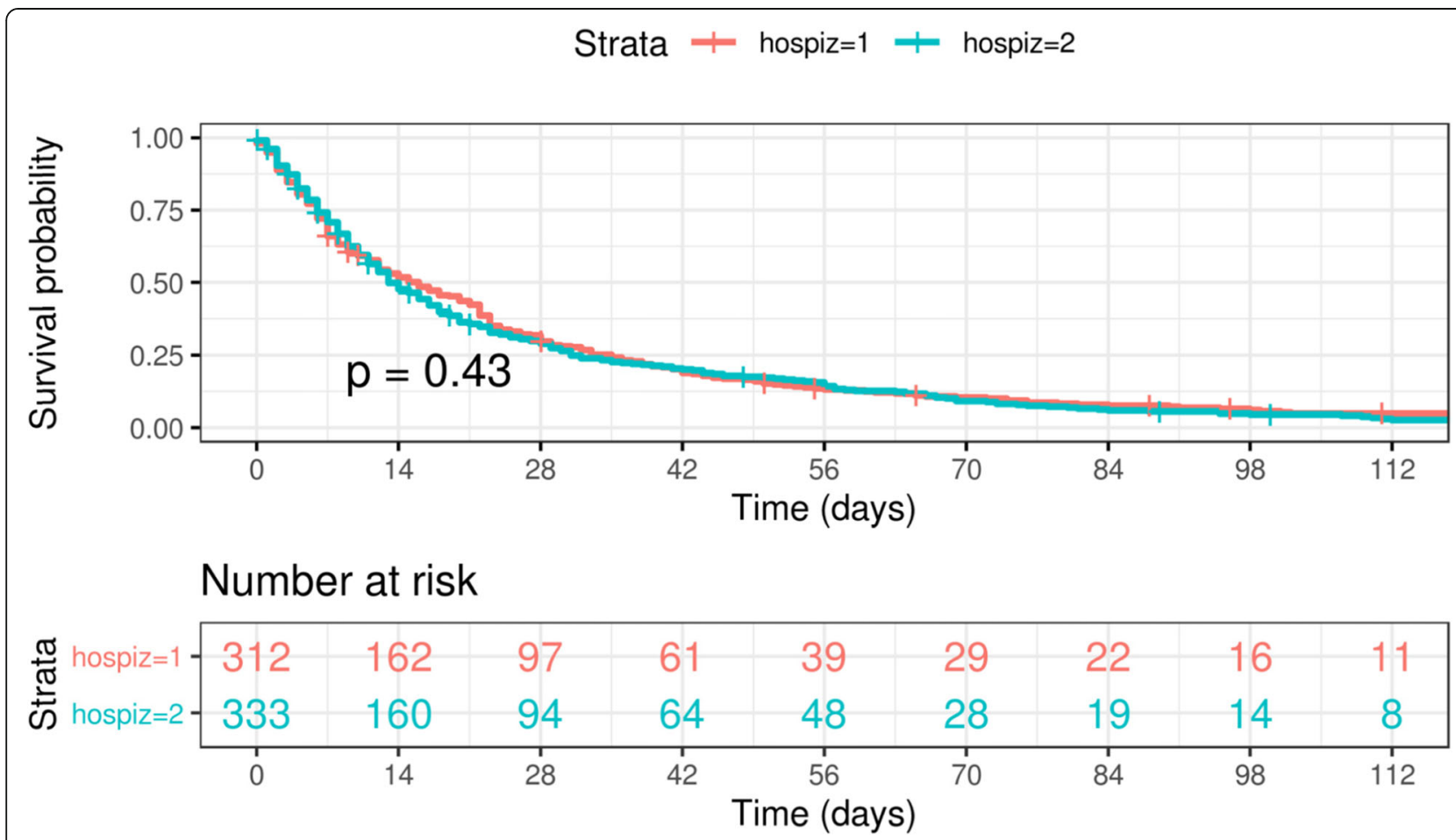

Fig. 1 Survival time for all patients with malignant disease 
Table 2 Patients with malignant primary disease and oncological therapy in two hospices

\begin{tabular}{|c|c|c|c|c|c|c|}
\hline \multirow{2}{*}{$\begin{array}{l}\text { Category and related } p \text {-value }^{a} \\
\text { Patients with oncological therapy in a hospice }(p<0.01)\end{array}$} & \multicolumn{2}{|c|}{$\begin{array}{l}\text { Hospice } 1 \\
\text { (H1) }\end{array}$} & \multicolumn{2}{|c|}{$\begin{array}{l}\text { Hospice } 2 \\
(\mathrm{H} 2)\end{array}$} & \multicolumn{2}{|c|}{ Total } \\
\hline & 33 & $11 \%$ & 6 & $2 \%$ & 39 & $6 \%$ \\
\hline Age in years (average) & \multicolumn{2}{|c|}{$\begin{array}{l}69 \text { (range: } 44- \\
93)\end{array}$} & \multicolumn{2}{|c|}{$\begin{array}{l}68 \text { (range: } 56- \\
87 \text { ) }\end{array}$} & \multicolumn{2}{|c|}{$\begin{array}{l}68 \text { (range: } 44- \\
93 \text { ) }\end{array}$} \\
\hline Residence time in days & \multicolumn{2}{|c|}{$\begin{array}{l}67 \text { (range: } 4- \\
440 \text { ) }\end{array}$} & \multicolumn{2}{|c|}{$\begin{array}{l}44 \text { (range: } 4- \\
100)\end{array}$} & \multicolumn{2}{|c|}{$\begin{array}{l}55 \text { (range: } 4- \\
440)\end{array}$} \\
\hline \multicolumn{7}{|l|}{ Gender } \\
\hline Male & 11 & $33 \%$ & 1 & $17 \%$ & 12 & $31 \%$ \\
\hline Female & 22 & $67 \%$ & 5 & $83 \%$ & 27 & $69 \%$ \\
\hline \multicolumn{7}{|l|}{ Malignant disease (primary diagnosis) } \\
\hline Bronchial carcinomas & 5 & $15 \%$ & 1 & $17 \%$ & 6 & $15 \%$ \\
\hline Gastrointestinal cancers & 7 & $21 \%$ & 0 & $0 \%$ & 7 & $18 \%$ \\
\hline Gynecological cancers & 10 & $30 \%$ & 4 & $67 \%$ & 14 & $36 \%$ \\
\hline Brain cancers & 1 & $3 \%$ & 1 & $17 \%$ & 2 & $5 \%$ \\
\hline ENT tract cancers & 1 & $3 \%$ & 0 & $0 \%$ & 1 & $3 \%$ \\
\hline Other cancer (bone cancers, thyroid carcinomas, skin malignomas, cancer of unknown pirmary) & 0 & $0 \%$ & 0 & $0 \%$ & 0 & $0 \%$ \\
\hline Urological cancers & 6 & $18 \%$ & 0 & $0 \%$ & 6 & $15 \%$ \\
\hline Hematological systemic diseases & 3 & $9 \%$ & 0 & $0 \%$ & 3 & $8 \%$ \\
\hline Indication of oncological therapies (multiple indications per patient, where applicable) & 41 & & 6 & & 47 & \\
\hline Dyspnea due to anaemia $(p=0.58)$ & 10 & $24 \%$ & 0 & $0 \%$ & 10 & $21 \%$ \\
\hline Diarrhea due to cancer disease $(p=1.00)$ & 2 & $5 \%$ & 0 & $0 \%$ & 2 & $4 \%$ \\
\hline Bone pain $(p=0.65)$ & 13 & $32 \%$ & 2 & $33 \%$ & 15 & $32 \%$ \\
\hline Meningeal cancer manifestation $(p=1.00)$ & 1 & $2 \%$ & 0 & $0 \%$ & 1 & $2 \%$ \\
\hline Continuation of ongoing anti-proliferative therapy $(p=0.01)$ & 0 & $0 \%$ & 2 & $33 \%$ & 2 & $4 \%$ \\
\hline Nausea/vomiting due to cancer disease $(p=1.00)$ & 1 & $2 \%$ & 0 & $0 \%$ & 1 & $2 \%$ \\
\hline Complications due to leukocytosis $(p=1.00)$ & 3 & $7 \%$ & 0 & $0 \%$ & 3 & $6 \%$ \\
\hline Pain therapy $(p=0.12)$ & 4 & $10 \%$ & 2 & $33 \%$ & 6 & $13 \%$ \\
\hline Other complications due to cancer disease $(p=1.00)$ & 3 & $7 \%$ & 0 & $0 \%$ & 3 & $6 \%$ \\
\hline Oncological therapy (multiple treatment, where applicable) & 41 & & 6 & & 47 & \\
\hline Anti-hormonal therapy $(p=0.27)$ & 5 & $12 \%$ & 2 & $33 \%$ & 7 & $15 \%$ \\
\hline Targeted therapies (antibody therapy, tyrosine kinase inhibitors, somatostatin analogues; $p=0.44$ ) & 4 & $10 \%$ & 2 & $33 \%$ & 6 & $13 \%$ \\
\hline Chemotherapy $(p=0.01)$ & 6 & $15 \%$ & 0 & $0 \%$ & 6 & $15 \%$ \\
\hline Radiotherapy $(p=0.01)$ & 6 & $15 \%$ & 0 & $0 \%$ & 6 & $13 \%$ \\
\hline Bisphosphonates $(p=0.02)$ & 10 & $24 \%$ & 2 & $33 \%$ & 12 & $26 \%$ \\
\hline Transfusions ( $p<0.01)$ & 10 & $24 \%$ & 0 & $0 \%$ & 10 & $21 \%$ \\
\hline \multicolumn{7}{|l|}{ Clinical course } \\
\hline Discharge & 2 & $6 \%$ & 1 & $17 \%$ & 3 & $8 \%$ \\
\hline Hospitalization & 1 & $3 \%$ & 1 & $17 \%$ & 2 & $5 \%$ \\
\hline For survival time see Fig. 2 & & & & & & \\
\hline
\end{tabular}

${ }^{a}$ Refers to the comparison of the two hospices

patients with bisphosphonates or without brain cancer have a lower instantaneous risk of mortality. Note that the statistical power is very low for the other therapies due to the small number of patients so that we cannot conclude that the other therapies do not have any relevant effect.
The most common indications for oncological therapy were dyspnea $(\mathrm{H} 1,24 \% ; \mathrm{H} 2,0 \%)$ and (bone) pain $(\mathrm{H} 1$, $42 \% ; \mathrm{H} 2,66 \%)$. Also the odds of receiving an oncological therapy were significantly higher for patients with dyspnea $(p=0.02)$ and bone pain $(p=0.01)$. In two patients in $\mathrm{H} 2$, anti-proliferative therapy was continued for 


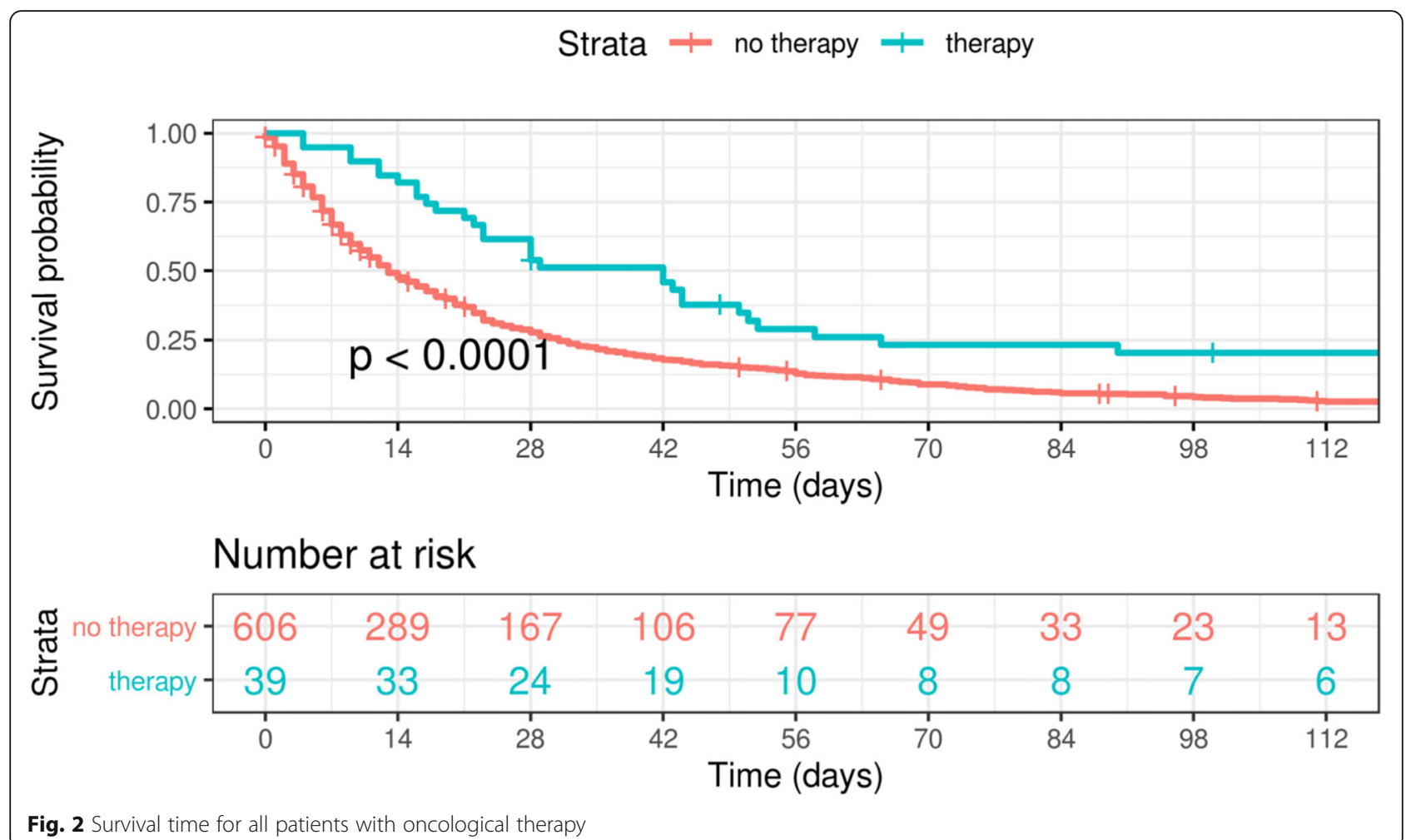

reasons that could not be retrospectively detected (Table 2). When symptoms were treated, bone pain was the most common treatment indication for bronchial carcinomas and gynaecological and urological cancers. In case of gastrointestinal cancers and cancers of the ENT tract, dyspnoea due to anaemia was in the foreground, and in case of brain cancers and haematological systemic diseases, complications due to the malignant disease were the most important reasons for oncological therapy (Table 5). However, there are only low differences between the treatment indications in general because of the low number of cases.

Dyspnoea was primarily caused by anaemia, which was treated, only in $\mathrm{H} 1$, by the transfusion of erythrocyte concentrates $(p<0.01)$. Bisphosphonates and antihormonal treatments (for gynaecological and urological cancers) were used for pain therapy in both hospices, but bisphosphonates were used significantly more often in $\mathrm{H} 1(p=0.02)$. In addition, radiotherapy and chemotherapy were only used in $\mathrm{H} 1$ ( $p=0.01$; Tables 2 and 5). Some of these therapies were used in combination. The

Table 3 Cox regression results for oncological therapy

\begin{tabular}{llll}
\hline & Hazard Ratio & 95\% Confidence Interval & $\boldsymbol{p}$ \\
\hline Oncological therapy & 0.49 & {$[0.34,0.71]$} & 0.0001 \\
Hospice & 1.03 & {$[0.87,1.21]$} & 0.7658 \\
Age & 1.01 & {$[1,1.02]$} & 0.0115 \\
Sex (female) & 0.82 & {$[0.68,0.99]$} & 0.0412 \\
Gastrointestinal cancer & 0.9 & {$[0.71,1.14]$} & 0.3987 \\
Gynaecological cancer & 0.83 & {$[0.63,1.1]$} & 0.191 \\
Haematological systemic disease & 1.41 & {$[0.95,2.1]$} & 0.0865 \\
Brain cancer & 0.62 & {$[0.45,0.87]$} & 0.0052 \\
ENT tract cancer & 0.69 & {$[0.45,1.05]$} & 0.0808 \\
Other cancer & 0.73 & {$[0.49,1.11]$} & 0.1426 \\
Urological cancer & 0.92 & {$[0.66,1.29]$} & 0.6391 \\
\hline
\end{tabular}


Table 4 Cox regression results for the type of oncological therapy

\begin{tabular}{llll}
\hline & Hazard Ratio & 95\% Confidence Interval & $\boldsymbol{p}$ \\
\hline Hospice & 1.02 & {$[0.86,1.2]$} & 0.8329 \\
Age & 1.01 & {$[1,1.02]$} & 0.0212 \\
Sex (female) & 0.82 & {$[0.68,0.99]$} & 0.0416 \\
Gastrointestinal cancer & 0.92 & {$[0.72,1.17]$} & 0.4854 \\
Gynaecological cancer & 0.86 & {$[0.65,1.13]$} & 0.2805 \\
Haematological systemic disease & 1.38 & {$[0.93,2.07]$} & 0.1133 \\
Brain cancer & 0.62 & {$[0.45,0.87]$} & 0.0053 \\
ENT tract cancer & 0.69 & {$[0.45,1.06]$} & 0.0873 \\
Other cancer & 0.75 & {$[0.49,1.13]$} & 0.1626 \\
Urological cancer & 0.94 & {$[0.67,1.32]$} & 0.7376 \\
Anti-hormonal therapy & 0.47 & {$[0.18,1.18]$} & 0.1064 \\
Radiotherapy & 0.54 & {$[0.22,1.36]$} & 0.1929 \\
Bisphosphonates & 0.48 & {$[0.25,0.91]$} & 0.0254 \\
Chemotherapy & 1.49 & {$[0.62,3.62]$} & 0.3751 \\
Transfusions & 0.5 & {$[0.24,1.02]$} & 0.0564 \\
Targeted therapies & 0.41 & {$[0.15,1.1]$} & 0.0771 \\
\hline
\end{tabular}

symptomatic complications of malignant disease were only treated in $\mathrm{H} 1$ with anti-proliferative therapies (Table 5). Transfusions $(n=10,21 \%)$, bisphosphonates $(n=12,26 \%)$ and anti-hormonal therapies $(n=7,15 \%)$ were the most common treatments for all patients with symptom-focused oncological treatment (Table 2).

\section{Discussion}

Whether and how cancer therapies should be used in patients with a highly advanced haematological/oncological disease is controversial presently [14, 15, 20-23], particularly for the residents of a hospice [19, 24-27]. To obtain actual insight into the use of symptomfocused cancer therapies at the end of life, all residents in the two hospices in Lower Bavaria were retrospectively examined.

The capacity of 10 beds with patient care by general practitioners and palliative care physicians is common in German hospices [31, 32]. The integration of $\mathrm{H} 1$ into an ESMO-certified network is beyond this standard and probably has an impact on the type of patient care.

Of the 706 residents examined, 645 (91\%) had a malignant disease; this predominance over non-cancer diseases is common in German hospices [32] and is reflected accordingly in the two hospices examined in this analysis. The average age of 72 years, slight predominance of women and average residence time of about 1 month were analogous to the general data of palliative and hospice patients in Germany [31-33]. The spread of the underlying malignant diseases, especially with regard to frequent cancer entities, was similar to the spread of cancer deaths in Germany [33]. This spread was approximately the same for both hospices. An exception were the haematological systemic diseases that were more frequently observed in $\mathrm{H} 1$ than in $\mathrm{H} 2(10 \%$ vs $2 \%$ of residents, $p<0.01)$. The integration of $\mathrm{H} 1$ into a network focusing on haematology and oncology is definitely an important factor. The conditions in $\mathrm{H} 2$ are more likely to reflect the reality in general care, especially because patients with a malignant haematological disease are under-represented in palliative care $[34,35]$ and the integration of a hospice into a haematological/oncological network is no standard in Germany.

Symptom-focused oncological therapies were used in both hospices, but only in a small number of patients (39 of 645 patients, 6\%). However, a comparison of both hospices showed a significant difference in the number of therapies used $(\mathrm{H} 1,11 \%, n=33 ; \mathrm{H} 2,2 \% ; n=6 ; \mathrm{p}<$ $0.01)$ for a comparable number of residents $(\mathrm{H} 1, n=312$; $\mathrm{H} 2, n=333)$. This may be due to the medical care provided and organizational integration of the hospices; general practitioners and palliative care physicians provide independent care in $\mathrm{H} 2$, whereas haematologists and oncologists are additionally present in $\mathrm{H} 1$, providing a multidisciplinary approach. The medical specialization and the interdisciplinary approach might contribute to the choice of symptom-focused therapies [6, 14]. In addition, $\mathrm{H} 1$ is strongly integrated with outpatient and inpatient oncological therapy facilities, which minimizes the organizational effort for certain therapies (e.g. transfusions or radiation therapy).

In addition to the above mentioned structural factors, various patient factors also seem to have an influence on the choice of therapy. In both hospices, those patients 
Table 5 Indication and resulting oncological therapy in patients with a malignant primary disease in a hospice

\begin{tabular}{|c|c|c|c|c|}
\hline Oncological disease & $\begin{array}{l}\text { Indication oncological } \\
\text { therapy }(\mathrm{H} 1)\end{array}$ & $\begin{array}{l}\text { Oncological therapy } \\
\text { (H1) }\end{array}$ & $\begin{array}{l}\text { Indication } \\
\text { oncological } \\
\text { therapy }(\mathrm{H} 2)\end{array}$ & $\begin{array}{l}\text { Oncological } \\
\text { therapy }^{\mathrm{a}}(\mathrm{H} 2)\end{array}$ \\
\hline \multirow[t]{3}{*}{ Bronchial carcinomas } & Bone pain & $\begin{array}{l}\text { Bisphosphonates }(n=3) \\
\text { Radiation }(n=1)\end{array}$ & $\begin{array}{l}\text { Continuation of } \\
\text { ongoing therapy }\end{array}$ & $\begin{array}{l}\text { Tyrosine kinase } \\
\text { inhibitor }(n=1)\end{array}$ \\
\hline & $\begin{array}{l}\text { Meningeal cancer } \\
\text { manifestation }\end{array}$ & $\begin{array}{l}\text { Intrathecal } \\
\text { chemotherapy }(n=1)\end{array}$ & none & none \\
\hline & $\begin{array}{l}\text { Dyspnea due to cancer } \\
\text { disease }\end{array}$ & $\begin{array}{l}\text { Intravenous } \\
\text { chemotherapy }(n=1)\end{array}$ & none & none \\
\hline \multirow[t]{4}{*}{ Gastrointestinal cancers } & Bone pain & Bisphosphonates $(n=1)$ & none & none \\
\hline & $\begin{array}{l}\text { Dyspnea due to } \\
\text { anaemia }\end{array}$ & $\begin{array}{l}\text { Erythrocyte transfusion } \\
(n=4)\end{array}$ & none & none \\
\hline & $\begin{array}{l}\text { Diarrhea due to cancer } \\
\text { disease }\end{array}$ & $\begin{array}{l}\text { Somatostatin analogues } \\
(n=2)\end{array}$ & none & none \\
\hline & $\begin{array}{l}\text { Complications due to } \\
\text { peritoneal } \\
\text { carcinomatosis }\end{array}$ & $\begin{array}{l}\text { Tyrosine kinase inhibitor } \\
(n=1)\end{array}$ & none & none \\
\hline \multirow[t]{4}{*}{ Gynecological cancers } & Bone pain & $\begin{array}{l}\text { Bisphosphonates }(n=4), \\
\text { Radiation }(n=1) \\
\text { Anti-hormonal therapy } \\
(n=2)\end{array}$ & Bone pain & $\begin{array}{l}\text { Bisphosphonates } \\
(n=2)\end{array}$ \\
\hline & Pain therapy & $\begin{array}{l}\text { Anti-hormonal therapy } \\
(n=2)\end{array}$ & Pain therapy & $\begin{array}{l}\text { Anti-hormonal } \\
\text { therapy }(n=2)\end{array}$ \\
\hline & $\begin{array}{l}\text { Dyspnea due to } \\
\text { anaemia }\end{array}$ & $\begin{array}{l}\text { Erythrocyte transfusion } \\
(n=2)\end{array}$ & none & none \\
\hline & $\begin{array}{l}\text { Nausea/vomiting due to } \\
\text { cancer disease }\end{array}$ & $\begin{array}{l}\text { Somatostatin analogues } \\
(n=1)\end{array}$ & none & none \\
\hline Brain cancers & $\begin{array}{l}\text { Complications due to } \\
\text { brain cancer }\end{array}$ & $\begin{array}{l}\text { Oral chemotherapy }(n= \\
\text { 1) Radiation }(n=1)\end{array}$ & $\begin{array}{l}\text { Continuation of } \\
\text { ongoing therapy }\end{array}$ & $\begin{array}{l}\text { Tyrosine kinase } \\
\text { inhibitor }(n=1)\end{array}$ \\
\hline ENT tract cancers & $\begin{array}{l}\text { Dyspnea due to } \\
\text { anaemia }\end{array}$ & $\begin{array}{l}\text { Erythrocyte transfusion } \\
(n=1)\end{array}$ & none & none \\
\hline $\begin{array}{l}\text { Other cancer (bone cancers, thyroid carcinomas, skin } \\
\text { malignomas, cancer of unknown pirmary) }\end{array}$ & none & none & none & none \\
\hline \multirow[t]{3}{*}{ Urological cancers } & Bone pain & $\begin{array}{l}\text { Bisphosphonates }(n=2) \\
\text { Radiation }(n=2)\end{array}$ & none & none \\
\hline & $\begin{array}{l}\text { Dyspnea due to } \\
\text { anaemia }\end{array}$ & $\begin{array}{l}\text { Erythrocyte transfusion } \\
(n=1)\end{array}$ & none & none \\
\hline & Pain therapy & $\begin{array}{l}\text { Radiation }(n=1) \text {, Anti- } \\
\text { hormonal therapy }(n= \\
\text { 1) }\end{array}$ & none & none \\
\hline \multirow[t]{2}{*}{ Hematological systemic diseases } & $\begin{array}{l}\text { Complications due to } \\
\text { leukocytosis }\end{array}$ & $\begin{array}{l}\text { Oral/subcutaneous } \\
\text { chemotherapy }(n=3)\end{array}$ & none & none \\
\hline & $\begin{array}{l}\text { Dyspnea due to } \\
\text { anaemia }\end{array}$ & $\begin{array}{l}\text { Erythrocyte transfusion } \\
(n=2)\end{array}$ & none & none \\
\hline
\end{tabular}

${ }^{a}$ multiple selections possible

who underwent symptom-focused oncological therapy lived significantly longer than those without oncological therapy - regardless of age, sex or malignant disease (HR $0.49, p<0.01$ ). Additionally patients with therapy had a significant prolonged stay in the hospice $(\mathrm{p}<0.01)$ and significantly lower odds of being discharged $(p=0.05)$. However, it is unlikely that the symptom-focused oncological therapies are the cause of longer survival. Almost all of these therapies have no known life-prolonging effect, and in the statistical analysis, surprisingly, only the bisphosphonates had a significant influence. But there is no know effect of bisphosphonates that causes a better survival and therefore the data should not be overstated. Rather, a screening of patients in a more stable general condition seems to have taken place prior to the initiation of symptom-focused oncological therapy. The change from a strict "either/or" concept to a combined approach of hospice care and supportive cancer therapy has first application for a specific patient group here [25-27]. 
Specific cancer therapies were used in both hospices for symptom relief. The most common indications were dyspnea (21\%) and (bone) pain (45\%). These are typical and commonly occurring conditions in patients with advanced and incurable diseases [35, 36]. Palliative care approaches are generally used here [35, 36]; however, symptom-focused oncological therapies have already been successfully applied and should not be excluded a priori for hospice residents; rather they can represent meaningful symptom-oriented therapies [6-10]. This is also reflected in the fact that in our analysis patients with dyspnea $(p=0.02)$ or bone pain $(p=0.01)$ had a significant greater chance to receive a symptom-focused oncological therapy than patients without. Cancerspecific complications, such as bone pain in bronchial carcinomas, urological and gynaecological cancers or dyspnoea due to anaemia in gastrointestinal cancers (Table 5), are known symptoms of these diseases [37]. Due to the overall low number of cases, a clear distinction or a symptom allocation specific to the entity is only possible to a limited extent; the transitions are often seamless. But symptom-focused oncological therapies tend to be more symptom-oriented than cancer-specific.

Dyspnoea as a common symptom due to anaemia in cancer patients can be successfully treated by the use of erythrocyte transfusions [38]. Interestingly, dyspnoea was only documented in $\mathrm{H} 1$ and was treated by erythrocyte transfusions also only in $\mathrm{H} 1(\mathrm{H} 1, n=10 ; \mathrm{H} 2, n=0$, $p<0.01)$. Due to the anticipated symptoms of patients in advanced stages, [35-37] it can be assumed that anaemia-related dyspnoea also occured in $\mathrm{H} 2$. However, the possibility of blood transfusion in a hospice is often quite complicated from an organizational point of view. In addition, the necessity of patients to undergo transfusion is often an obstacle for admission to a hospice [9], but hospice patients may have a greater acceptability of transfusions than nurses [39]. H1 was able to solve these problems through its integration into a network focusing on haematology and oncology. The same applies to the difference in the use of radiotherapeutic interventions for pain relief (H1, $n=6 ; \mathrm{H} 2, \mathrm{n}=0, p=0.01)$. Short-term radiotherapy can lead to a significant reduction in pain, save painkillers and improve the quality of life [8]. However, there are also large organizational barriers for a hospice, which can be solved through cooperation, as observed for H1. Bisphosphonates, a potential useful coanalgesic $[11,12]$ for painful bone metastases or rather useful in preventing bone pain [40], were used according to the required ESMO clinical practice guidelines [12] in both hospices. In terms of figures, the more oncologyoriented $\mathrm{H} 1$ significantly prevailed in the number of cases in whom bisphosphonates were used $(p=0.02)$. In palliative condition, the use of anti-proliferative drugs in patients is controversial with distinct advantages $[13,16$,
41, 42] and disadvantages [20-22]. However, the use of chemotherapy as a symptom-controlling therapy seems to be beneficial for patients with a very advanced disease $[41,42]$ or even in hospices [13]. Chemotherapy can be used in hospices only in a subgroup of carefully screened and symptomatic patients. In our analysis, only a small number of patients underwent chemotherapy (13\% patients undergoing oncological therapy, corresponding to $0.9 \%$ of all patients with oncological disease in the hospice). The structural prerequisites seem to be necessary here because chemotherapies were only used in $\mathrm{H} 1$ ( $p=$ 0.01 ).

\section{Limitations}

The study has some limitations. The analysis was undertaken only at two hospices, with partially significant structural differences. The study-design was retrospective and not close to a randomized trial or a propensityweighted comparison. Therefore, the data must be estimated under these restrictions. Because of the small number of patients with an oncological therapy, the statistical power is low for some of the statistical tests. A representative statement regarding the use of symptomfocused oncological therapies in hospices throughout Germany therefore cannot be made. The results mainly describe the use and indication of oncological therapies for hospice residents. No statement can be made regarding the resulting effect on the quality of life and on the burden of symptoms - especially for patients with an ECOG 3 or 4 - because this information could not be retrospectively recorded on the basis of the available data. For the same reason, no comment can be made on the general preferences of patients and their relatives regarding the use of symptom-focused oncological therapies in hospices.

\section{Conclusion}

Despite the limitation mentioned above, it is apparent that the use of symptom-focused oncological therapies in hospices is possible and will be further conducted. The focus here is on improving the burden of symptoms and thus the quality of life via the therapies applied and not on prolonging life. Hence, cancer-directed therapies could sometimes be an important part of the best palliative strategy. However, the indication for the use of such a therapy could well be related to the training focus of the attending physicians and the integration of hospices into network structures. It seems reasonable to include haematologists/oncologists and radiation therapists next to non-oncologists/palliative physicians in the care of hospice patients, to achieve the best possible care for hospice residents. The strict distinction between hospice and oncological cares of patients with a far advanced and incurable disease should be abandoned in favour of 
a combined and parallel treatment. The best possible therapy options can therefore be available to patients at any time. Initial approaches for a combined care already seem to exist.

\section{Abbreviations}

ESMO: European Society for Medical Oncology; H1: Hospice 1; H2: Hospice 2; HR: Hazard Ratio

\section{Acknowledgements}

We would like to acknowledge Enago for its support in translating the work into English. We acknowledge support by the German Research Foundation and the Open Access Publication Funds of the Göttingen University.

\section{Authors' contributions}

FK, UV-K and UK were responsible for the study design, data analysis and data interpretation as well as for writing the manuscript. AH was responsible for data collection and data preparation. N-CM was responsible for data analysis and data interpretation. FKü was responsible for statistical analysis and for data interpretation. All authors read and approved the final manuscript.

\section{Funding}

Open Access funding enabled and organized by Projekt DEAL.

\section{Availability of data and materials}

The datasets used and/or analysed during the current study are available from the corresponding author on reasonable request.

\section{Ethics approval and consent to participate}

According to the Ethics Committee Munich, an ethical approval was not required for this analysis.

\section{Consent for publication}

Not applicable.

\section{Competing interests}

The authors declare that they have no competing interests.

\section{Author details}

${ }^{1}$ University Hospital Regensburg, Clinic and Polyclinic for Internal Medicine III, Regensburg, Germany. ${ }^{2}$ VK\&K Studien GbR, Landshut, Germany. ${ }^{3}$ Department of Medical Statistics, University Medical Center Göttingen, Göttingen, Germany. ${ }^{4}$ University Medicine Göttingen, Clinic for Gastroenterology and Gastrointestinal Oncology, Göttingen, Germany. ${ }^{5}$ University Medicine Göttingen, Clinic for Haematology and Medical Oncology,

Robert-Koch-Straße 40, 37075 Göttingen, Germany.

Received: 21 January 2020 Accepted: 6 September 2020

Published online: 12 September 2020

\section{References}

1. Temel JS, Greer JA, Muzikansky A, et al. Early palliative care for patients with metastatic non-small-cell lung cancer. N Engl J Med. 2010;363:733-42.

2. Farbicka P, Nowicki A. Palliative care in patients with lung cancer. Contemp Oncol (Pozn). 2013;17:238-45.

3. Hui D, Bruera E. Integrating palliative care into the trajectory of cancer care. Nat Rev Clin Oncol. 2016;13:159-71.

4. Parikh $R$, Kirch $R$, Smith $T$, et al. Early specialty palliative care - translating data in oncology into practice. N Engl J Med. 2013;369:2347-51.

5. Howie L, Peppercorn J. Early palliative care in cancer treatment: rationale, evidence and clinical implications. Ther Adv Med Oncol. 2013;5:318-23.

6. Park K, Lee $C$, Tseng $Y$, et al. Palliative radiation therapy in the last 30 days of life: a systematic review. Radiother Oncol. 2017:125:193-9.

7. Barthelemy N, Jansen N, Gennigens C, et al. Does radiotherapy have a role in end-of-life care? Rev Med Liege. 2012;67:128-32.

8. van Oorschot B, Schuler M, Simon A, et al. Patterns of care and course of symptoms in palliative radiotherapy: a multicenter pilot study analysis. Strahlenther Onkol. 2011;187:461-6.

9. LeBlanc T, Egan P, Olszewski A. Transfusion dependence, use of hospice services, and quality of end-of-life care in leukemia. Blood. 2018;132:717-26.
10. Orme J, Still D, Day R, et al. The experiences of patients undergoing blood transfusion in a day hospice. Int J Palliat Nurs. 2013;19:171-6.

11. Mitra R, Jones S. Adjuvant analgesics in cancer pain: a review. Am J Hosp Palliat Care. 2012;29:70-9.

12. Fallon M, Giusti R, Aielli F, et al. Management of cancer pain in adult patients: ESMO clinical practice guidelines. Ann Oncol. 2018:29:166-91.

13. Schonwetter R, Roscoe L, Nwosu M, et al. Quality of life and symptom control in hospice patients with cancer receiving chemotherapy. J Palliat Med. 2006;9:638-45.

14. Haverhals L, Manheim C, Mor V, et al. The experience of providing hospice care concurrent with cancer treatment in the VA. Support Care Cancer. 2019;27:1263-70.

15. Mor V, Joyce N, Coté $D$, et al. The rise of concurrent care for veterans with advanced cancer at the end of life. Cancer. 2016;122:782-90.

16. Mor V, Wagner T, Levy C, et al. Association of Expanded VA hospice care with aggressive care and cost for veterans with advanced lung Cancer. JAMA Oncol. 2019:5:810-6.

17. Loriot $Y$, Miller K, Sternberg C, et al. Effect of enzalutamide on health-related quality of life, pain, and skeletal-related events in asymptomatic and minimally symptomatic, chemotherapy-naive patients with metastatic castration-resistant prostate cancer (PREVAlL): results from a randomised, phase 3 trial. Lancet Oncol. 2015;16:509-21.

18. Tombal B, Saad F, Penson D, et al. Patient-reported outcomes following enzalutamide or placebo in men with non-metastatic, castration-resistant prostate cancer (PROSPER): a multicentre, randomised, double-blind, phase 3 trial. Lancet Oncol. 2019:20:556-69.

19. van Oorschot B. Krebs im Endstadium: Überengagierte Versorgung am Lebensende. Dtsch Arztebl. 2018;115:16. https://doi.org/10.3238/PersOnko. 2018.3211.3223.3203.

20. Prigerson $\mathrm{H}$, Bao Y, Shah $M$, et al. Chemotherapy use, performance status, and quality of life at the end of life. JAMA Oncol. 2015;1:778-84.

21. Zhang B, Nilsson M, Prigerson $\mathrm{H}$. Factors important to patients' quality of life at the end of life. Arch Intern Med. 2012;172:1133-42.

22. Wu C, Hsu T, Chang C, et al. Palliative chemotherapy affects aggressiveness of end-of-life care. Oncologist. 2016;21:771-7.

23. Kaur J, Mohanti B. Transition from curative to palliative Care in Cancer Indian J Palliat Care. 2011;17:1-5.

24. Casarett D, Fishman J, Lu H, et al. The terrible choice: re-evaluating hospice eligibility criteria for cancer. J Clin Oncol. 2009;27:953-9.

25. Casarett D, Van Ness P, O'Leary J, et al. Are patient preferences for lifesustaining treatment really a barrier to hospice enrollment for older adults with serious illness? J Am Geriatr Soc. 2006;54:472-8.

26. Casarett D, Fishman J, O'Dwyer P, et al. How should we design supportive cancer care? The patient's perspective. J Clin Oncol. 2008;26:1296-301.

27. Balboni T. Hospice and anticancer therapy-shifting from an either/or to a both/and treatment model. JAMA Oncol. 2019;5:786-7.

28. Team RC. R: A Language and Environment for Statistical Computing. Vienna: R Foundation for Statistical Computing; 2018. https://www.R-projectorg/.

29. Kassambara, Alboukadel, Kosinski. Survminer: Drawing survival curves using 'Ggplot2'. 2019 https://CRAN.R-projectorg/package=survminer.

30. Therneau T. A Package for Survival Analysis in S. 2015 https://CRAN.Rprojectorg/package=survival.

31. Robert Koch Institute and Destatis. Health in Germany. Health reporting by the federal government. 2015 https:/www.rkide/DE/Content/ Gesundheitsmonitoring/Gesundheitsberichterstattung/GeslnDtld/gesundheit in_deutschland_2015pdf?_blob=publicationFile Accessed 27 Oct 2019.

32. Jansky M, Nauck F, Jasper B. Gutachten zum Bedarf an Hospizbetten in Nordrhein-Westfalen. 2017 https://alpha-nrw.de/wp-content/uploads/2017/ 05/gutachten_bedarf_hospizbetten_nrw_2017.pdf. Accessed 03 Oct 2019.

33. Cancer in Germany 2013/2014. 11. Edition: Robert Koch Institute and the Society of Epidemiological Cancer Registry in Germany. 2017 https:/www.krebsdaten.de/ Krebs/DE/Content/Publikationen/Krebs_in_Deutschland/kid_2017//Krebs_in _ deutschland_2017.pdf?_blob=publicationFile. Accessed 27 Oct 2019.

34. Oechsle K. Palliative Care in Patients with hematological malignancies. Oncol Res Treat. 2019;42:25-30

35. Kaiser $F$, Rudloff $L$, Vehling-Kaiser $U$, et al. Palliative home care for patients with advanced haematological malignancies-a multicenter survey. Ann Hematol. 2017:96:1557-62

36. Schneider W, Eichner E, Thoms U, et al. Specialised out-patient palliative care (SAPV) in Bavaria: efficiency, structural and process-related effects and rural care. Gesundheitswesen. 2015;77:219-24. 
37. German Society for Hematology and Medical Oncology. 2019. https://www. onkopedia.com/de/onkopedia/guidelines. Accessed 27 Oct 2019.

38. Mercadante S, Ferrera P, Villari P, et al. Effects of red blood cell transfusion on anemia-related symptoms in patients with cancer. J Palliat Med. 2009;12: 60-3.

39. Meystre C, Burley N, Ahmedzai S. What investigations and procedures do patients in hospices want? Interview based survey of patients and their nurses. BMJ. 1997;1997:1202-3.

40. Porta-Sales J, Garzón-Rodríguez C, Llorens-Torromé S, et al. Evidence on the analgesic role of bisphosphonates and denosumab in the treatment of pain due to bone metastases: a systematic review within the European Association for Palliative Care guidelines project. Palliat Med. 2017;31:5-25.

41. Tannock I, Osoba D, Stockler M, et al. Chemotherapy with mitoxantrone plus prednisone or prednisone alone for symptomatic hormone-resistant prostate cancer: a Canadian randomized trial with palliative end points. J Clin Oncol. 1996;14:1756-64.

42. Lahoud M, Kourie H, Antoun J, et al. Road map for pain management in pancreatic cancer: a review. World J Gastrointest Oncol. 2016;8:599-606.

\section{Publisher's Note}

Springer Nature remains neutral with regard to jurisdictional claims in published maps and institutional affiliations.

Ready to submit your research? Choose BMC and benefit from:

- fast, convenient online submission

- thorough peer review by experienced researchers in your field

- rapid publication on acceptance

- support for research data, including large and complex data types

- gold Open Access which fosters wider collaboration and increased citations

- maximum visibility for your research: over $100 \mathrm{M}$ website views per year

At $\mathrm{BMC}$, research is always in progress.

Learn more biomedcentral.com/submissions 